\title{
On the Expansion of Classroom Teaching Space of Vocal Music for Music Majors in Colleges and Universities
}

\author{
Xiaomei An \\ Musical Department, College of Art, Huzhou University, Associate Professor, Tianshui City, Gansu Province, Research \\ direction: Vocal singing and teaching research.

\begin{abstract}
Institutions of higher learning aim at cultivating high-quality talents that can promote social construction and development. Therefore, when teaching teachers, in addition to explaining the key theoretical knowledge to students, teachers also need to carry out professional skills, comprehensive literacy and learning ability. Only by paying attention can students gain more comprehensive development. Therefore, how to expand the teaching space so that students can ensure the improvement of learning efficiency under the mobilization of learning enthusiasm when participating in vocal classroom learning activities is the main question explored in this article.
\end{abstract}

Keywords: Teaching space; higher education; teaching methods; vocal music classroom

\begin{abstract}
Teaching space is where teachers can break the inherent mode of thinking and extend classroom teaching activities outside the classroom when teaching, so that students in different learning environments can not only ensure the mobilization of learning enthusiasm, but also lead by teachers Next, improve learning efficiency. Therefore, the teaching space can help teachers to establish a high-quality classroom teaching environment through the optimization of teaching activities with its own characteristics of limitation, nature, extensibility and sociality. Vocal music classrooms in colleges and universities can enable students to learn their musical knowledge and singing methods, not only improve their singing skills, but also enable students to improve their aesthetic ability, artistic cultivation and musical literacy. Therefore, in order to ensure the orderly development of vocal teaching activities of music majors, teachers need to find teaching strategies that inspire students' learning initiative through the development of teaching space, so as to ensure the high-quality development of teaching activities and promote the advancement of higher music education in China Great development.
\end{abstract}

\section{Establish the correct teaching space concept and actively carry out practical activities}

The classroom is not only the main place for teachers to teach, but also the constituent elements of the teaching space. If teachers confuse the teaching space with classroom teaching when conducting vocal classroom teaching activities, it will not only make students lack a practical platform to fully demonstrate themselves, but also make it difficult to carry out on-site teaching and social activities, and affect the actual role of the teaching space. Go to the ground and affect the effective establishment of high-quality vocal classrooms. This requires teachers to combine the actual teaching situation, establish the correct teaching space concept, break through the limitations of the old teaching mode, and extend the vocal music classroom to activities outside the school. In this way, not only can the teaching content be effectively enriched, but students can also mobilize their enthusiasm to actively participate in vocal classroom knowledge learning in a variety of learning environments, thereby ensuring the rapid improvement of learning efficiency.

Copyright (C) 2020 Xiaomei An

doi: 10.18282/le.v9i5.1224

This is an open-access article distributed under the terms of the Creative Commons Attribution Non-Commercial License

(http://creativecommons.org/licenses/by-nc/4.0/), which permits unrestricted non-commercial use, distribution, and reproduction in any medium, provided the original work is properly cited. 
For example, in order to ensure the smooth extension of the teaching space, teachers can change the teaching method of instilling theoretical knowledge into students when conducting vocal classroom teaching activities. Through the development of vocal performance practical activities, students can choose corresponding activities according to their learning interests. Some students choose Bel Canto, some students choose popular songs to sing, and others show their talents in the form of musicals. In this dynamic practical classroom, not only the student's enthusiasm for learning is greatly enhanced, but also in the process of participating in singing performances, students can also grasp the typhoon grasp, shape, grace, stage gestures, expressions and microphones under the guidance of teachers. Use methods to learn. This can not only effectively improve students' singing skills, but also develop more comprehensive development in the process of training students' practical ability.

\section{Enrich teaching space and improve teaching methods}

Teaching space, as an overlap of various spaces, not only contains diverse content, but also can effectively improve the learning quality of students. Therefore, when conducting vocal teaching activities, teachers need to enrich the form of teaching space through in-depth research on the thinking consciousness of college students, and through the improvement of teaching methods, students can experience the fun of participating in vocal knowledge learning while mobilizing their enthusiasm for learning. Then achieve the purpose of promoting the orderly development of teaching activities. This requires teachers to keep up with the wave of teaching reform, improve and innovate the structure of the teaching space, and through the arrangement of various teaching elements, choose teaching methods that can be consistent with the current teaching content. This will not only create a vocal music classroom that attracts students' attention, but also enable students to continuously improve their musical literacy, singing level, and vocal cultivation through the study of singing skills and musical knowledge, and grow into high-quality musical talents needed by the country.

\section{Improve the teaching space framework and enhance students' enthusiasm for learning}

In order to effectively extend the teaching space, teachers need to improve their frameworks when conducting vocal classroom teaching activities. In order to establish high-quality vocal classrooms, students can be motivated to learn and complete their knowledge. . On the one hand, teachers need to add the music equipment needed in the teaching activities through the characteristics of the vocal teaching curriculum, and use Internet technology to enrich the content of the lectures, so that the network teaching space and the traditional teaching space can complement each other, and encourage students to have When learning is needed, whether it is on the online platform or offline classroom teaching activities, can meet the needs of learning vocal knowledge and singing skills. On the other hand, the teaching space is mainly composed of psychological space, cultural space, practice space and communication space. It is difficult for traditional vocal classroom teaching activities to excavate the value of teaching space to help students get better development. Therefore, through the improvement of the teaching space framework, teachers can use various cultural resources and social activities to carry out vocal teaching, so that students can not only ensure the improvement of learning quality, but also have a practical venue for applying knowledge. In the process of mobilizing students' enthusiasm for learning, it will promote the smooth development of teaching activities.

\section{Conclusion}

All in all, college students have strong learning abilities and have a strong enthusiasm for inquiry under the extension of thinking consciousness. Therefore, in order to ensure the smooth development of the vocal music classroom, so that students can better grasp the knowledge of music theory and singing skills under the enthusiasm of learning, they need to actively find ways to extend the teaching space through the breakthrough of old teaching concepts. This not only enables students to participate in more diverse forms of vocal music classrooms, but also stimulates learning enthusiasm, but also effectively improves the quality and effectiveness of learning, and promotes the efficient completion of 
classroom teaching activities.

\section{References}

1. Tang Yinling. The development and utilization of local music culture in the curriculum resources of music majors in ethnic local colleges and universities___ Taking Jishou University School of Music and Dance as an example[J]. The House of Drama, 2020(14):179.

2. Wang Mingyuan. Research on the Optimization Method of Digital Multimedia Technology in College Music Teaching in the Information Age_C Comment on "College Music Teaching and Multimedia Technology Application”[J]. Chinese Science and Technology Papers, 2020, 15(05): 605.

3. Fei Yujun. Several Problems and Reflections on the Inheritance and Development of the Idea of the Chinese Vocal Music School in the New Era_-Taking the Construction of Music Majors in Universities as an Example[J]. China Rural Education, 2020(12):30-31. 